\title{
Physical activity and sedentary behavior in preschoolers: a longitudinal assessment of trajectories and determinants
}

Einat A. Schmutz ${ }^{1}$, Sarah R. Haile ${ }^{1}$, Claudia S. Leeger-Aschmann'1, Tanja H. Kakebeeke ${ }^{2,7}$, Annina E. Zysset ${ }^{2}$, Nadine Messerli-Bürgy ${ }^{3,4}$, Kerstin Stülb ${ }^{3}$, Amar Arhab ${ }^{4}$, Andrea H. Meyer ${ }^{5}$, Simone Munsch ${ }^{3 \dagger}$, Jardena J. Puder ${ }^{4,6 \dagger}$, Oskar G. Jenni ${ }^{2,7+}$ and Susi Kriemler ${ }^{1 * \dagger}$

\begin{abstract}
Background: Despite physical activity (PA) being recognized as a critically important factor for good physical and mental health already early in life and throughout the life course, prospective data on activity behavior during the preschool years remains scarce. This study examined trajectories and determinants of levels and change in total PA (TPA), moderate-to-vigorous PA (MVPA) and sedentary behavior (SB) in a representative sample of Swiss preschoolers.

Methods: Data were drawn from the Swiss Preschoolers' Health Study (SPLASHY), a multi-site prospective cohort study including 555 children (53\% boys) aged 2-to-6 years at baseline. A follow-up was conducted after 12 months. Activity behavior was measured using accelerometers. Information on 35 potential determinants from different socio-ecological domains was either directly measured or parent-reported. Trajectories of TPA, MVPA and SB over time were described for boys and girls. Linear mixed models were used to investigate factors that predicted levels and change in TPA, MVPA and SB.

Results: All children were sufficiently physically active according to published recommendations for preschoolers. Trajectory profiles revealed a marked increase in TPA and MVPA in boys and girls whereas SB remained fairly stable over time. Mixed modeling demonstrated that variables most relevant to determining PA levels were sex, age and activity temperament (all positively associated). Together with gross motor skills, birth weight, family structure (only for TPA) and season (only for MVPA), these factors accounted for 26 and 32\% of total variance explained in TPA and MVPA, respectively. Activity temperament emerged as the strongest determinant of SB (negative association) and explained with sex, season and family structure $20 \%$ of total variance in SB. The presence of older siblings was the only factor that predicted change in PA over time.

Conclusions: In this healthy physically active cohort of preschoolers, non-modifiable individual-level factors had the greatest influence on PA. The limited success of this and previous studies to identify modifiable determinants and the finding that most preschoolers were sufficiently active suggest that future attempts should provide insights into how preschoolers' activity levels can be maintained and fostered to prevent subsequent harmful declines attributable, amongst others, to educational transitions. Thus, good-quality longitudinal studies are needed.
\end{abstract}

Trial registration: Current Controlled Trials ISRCTN41045021 (date of registration: 21.03.14).

Keywords: Children, Preschool, Physical activity, Sedentary behavior, Determinants, Trajectories, SPLASHY

\footnotetext{
* Correspondence: susi.kriemlerwiget@uzh.ch

${ }^{\dagger}$ Equal contributors

'Epidemiology, Biostatistics and Prevention Institute, University of Zurich,

Hirschengraben 84, 8001 Zurich, Switzerland

Full list of author information is available at the end of the article
} 


\section{Background}

Increased physical activity (PA) in the preschool age has been shown to be positively associated not only with decreased adiposity, but also with improved measures of psychosocial health, motor skill development, and cardiometabolic health indicators [1]. Thus, it is recommended that preschoolers engage in PA every day for at least $3 \mathrm{~h}$ and minimize the amount of time spent being sedentary [2-4]. Whether young children are sufficiently physically active and how PA changes over time during the preschool years is unclear; while a number of studies have reported engagement in sufficient levels of PA [5-7], others have found that preschool children do not meet the guidelines $[8,9]$. Moreover, two studies in children aged 3 to 4 years at baseline showed an increase in PA over 1 to 2 years [10, 11], whereas others found substantial declines [12].

Healthy habits and behaviors, such as PA and sedentary behavior (SB), are typically established during early childhood. Evidence suggests that these behaviors track into later life [13]. To support establishing healthy levels of PA and SB in childhood, the early identification of factors associated with these behaviors is an important research focus $[1,14]$. Since PA is a complex behavior with different levels of influence, the socio-ecological model [15] has been widely used to structure the study of potential correlates and determinants. Applying a social-ecological perspective, variables from different domains (demographic and biological; psychological, cognitive and emotional; behavioral; social and cultural; and environmental) can be explored. Numerous studies have examined potential influences in order to understand children's PA behavior and develop more targeted interventions. However, previous interventional studies aiming at promoting PA in children have had limited efficacy [16, 17]. A possible explanation why past attempts have largely proven unsuccessful involves the meaningful interpretation of evidence, which has mainly relied on cross-sectional data [16]. Such analyses take measurements of the outcome variable at only one time point into account. Where outcome measurements from additional time points are available, data are considered to be longitudinal and corresponding mixed model regression analysis can be applied. These models use all available measurements and take multiple measurements from each subject into account, resulting in more reliable results than using simple cross-sectional data. Whereas a large number of observational studies examined the correlates of PA in the early years, few have provided longitudinal data. Thus, to advance the field and establish a robust evidence base that can inform the design of effective behavior change interventions, research has called for studies that employ a prospective design to explore the whole spectrum of the social-ecological model within one study $[16,18]$.
Results from the few previous longitudinal studies on determinants of young children's PA levels have been inconsistent. A recent systematic review on determinants during the early years (age 0-6 years) found only sex and time spent playing to be positively associated with TPA while no consistent determinant was identified for MVPA [16]. Regarding SB, there has not been enough evidence to draw conclusions [19, 20]. It is important to recognize that determinants of activity levels may differ from determinants of rates of change in these levels. For a full understanding of the complexities with regard to participation in, barriers to, and preferences for PA in this age group, predictors of activity levels (subsequently called determinants) as well as those of changes in these levels (subsequently called determinants of change) is required. A recent publication synthesizing quantitative literature from longitudinal studies in preschool-aged children concluded that of 44 studied determinants of change only parental monitoring of their child's physical activity was consistently associated with change in physical activity [21]. Childcare provider training emerged as a determinant of change in MVPA.

Building upon previous work, the aim of the current study was threefold: (1) to describe trajectories of TPA, MVPA and SB over time in boys and girls, (2) to examine associations between potential determinants and TPA, MVPA and SB, and (3) to investigate associations between potential determinants of change and TPA, MVPA and SB.

\section{Methods}

\section{Study population and data collection}

Data were drawn from the Swiss Preschoolers' Health Study (SPLASHY), a multi-site prospective cohort study including 555 children aged 2 to 6 years from 84 childcare centers located in five cantons of Switzerland (covering 50\% of the Swiss population in 2013). A detailed description of the study design has been published elsewhere [22]. Data collection was conducted in the childcare centers in 2014 and 1 year later by the same study team in parallel at all study sites. While children recruited in $2014(n=476)$ could participate in a follow-up assessment 1 year later, those recruited in $2015(n=79)$ had a baseline assessment only. Baseline (T0) and follow-up (T1) data are used in the current study. Ethical approval is in accordance with the Declaration of Helsinki and has been obtained from all local ethical committees, with the Ethical Committee of the Canton of Vaud (No 338/13) being the main approving authority. Children and parents provided informed consent.

\section{Outcome variables: TPA, MVPA and SB}

$\mathrm{PA}$ and $\mathrm{SB}$ were objectively monitored for seven consecutive days using a hip-worn accelerometer measuring tri-axial 
acceleration (wGT3X-BT, ActiGraph, Pensacola, FL, USA). At both assessment time points, participants were instructed to wear the monitor $24 \mathrm{~h}$ /day except during water-based activities. PA data was sampled at a frequency of $30 \mathrm{~Hz}$, downloaded in three-second epochs and aggregated to 15-s epochs. Non-wear periods, defined as $\geq 20$ min of consecutive zero counts on all axes [23], and nighttime hours (9 pm to $7 \mathrm{am}$ ) were excluded. A minimum of 3 days, including one weekend day, with at least $10 \mathrm{~h}$ of recording per day were required for inclusion in analysis. Accelerometry data were expressed as TPA (accelerometry counts per min [cpm], averaged over the recording time) and as time spent at different activity intensities (min/day). Besides comparability considerations, accelerometer cut-points were chosen based on recent findings [24] showing that best classification accuracy has been achieved for the validated pediatric cutpoints of Pate RR, Almeida MJ, Mclver KL, Pfeiffer KA and Dowda M [25] for MVPA ( $\geq 420$ counts per $15 \mathrm{~s}$ ) and Evenson KR, Catellier DJ, Gill K, Ondrak KS and McMurray RG [26] for SB ( $\leq 25$ counts per $15 \mathrm{~s}$ ).

\section{Potential determinants}

In this work, the term determinant is used to describe a factor whose variation is followed systematically by variations in PA [27]. Previous research and the socioecological model guided the selection of potential determinants, which were classified into five domains [23]: (i) biological and demographic; (ii) psychological, cognitive and emotional; (iii) behavioral; (iv) social and cultural; and (v) environmental. A detailed description of all potential determinants is provided in Additional file 1.

\section{Statistical analysis}

Descriptive statistics are presented as mean (standard deviation $[\mathrm{SD}]$ ) for continuous variables and percentages for categorical variables, unless stated otherwise. To describe trajectories in $\mathrm{PA}$ and $\mathrm{SB}$ on the population level (aim 1), we present observed mean levels of TPA, MVPA and SB for different age categories ranging from two-and-a-half to six-and-a-half years for boys and girls separately. Differences between age groups were tested for using linear mixed models with categorical age as a single fixed effect and random intercepts for both child and childcare center. To examine associations between potential determinants and TPA, MVPA and SB over all time points (aim 2), linear mixed models for the outcome (at either time point) were used. Potential determinants, time point of assessment and accelerometer wear time were entered into the model simultaneously as fixed effects. Random intercepts were included for each childcare center and each subject (nested within childcare center). Factors for which there was at least some indication for an association with the outcome (i.e., $p \leq 0.10$ ) were subsequently included in the final model. Associations between potential determinants (assessed at T0) of changes in TPA, MVPA and SB from baseline to follow-up (aim 3) were examined by linear mixed modeling including a random intercept for childcare center. A change score could be calculated for $n=454$. One alternative model would have been ANCOVA (PA at T1 as a function of PA at T0 and other covariates) but we wanted to model the effects of potential determinants on the change in PA directly. To avoid regression to the mean, we regressed the change on the average of the baseline and follow-up PA instead of adjusting for baseline values [28]. All analysis steps for aim 1, 2 and 3 were defined a priori and not changed or added to after examining the results.

Collinearity diagnostics indicated that no significant multicollinearities were present. $P$-values obtained in the final models were used to quantify the explanatory power of potential determinants, i.e. the smaller the $p$-value, the stronger the evidence for an association with the outcome. $\mathrm{R}^{2}$ was calculated for the final models to capture the amount of variance explained; Marginal $R^{2}$ (variance explained by fixed effects) and conditional $R^{2}$ (variance explained by fixed and random effects) were estimated as described by Nakagawa S and Schielzeth H [29]. To check the form of the association between sex and age and a potential interaction, we considered two models: (a) age and sex as main effects and (b) age and sex as main effects plus their interaction. Since these analyses led to comparable results, only the main effects model (a) is presented here.

Missing data in both outcome and covariates were imputed using the MICE (Multiple Imputation Chained Equations) procedure [30]. While a complete case analysis may be straightforward to implement, it relies on stronger missing data assumptions than multiple imputation (MI) and can result in biased and less powerful estimates [31, 32]. The imputation model contained all variables included in the analysis model and the form of the variables was the same in both models [33]. There were no differences in key baseline characteristics (BMI, SES, siblings, parental BMI and family structure) between individuals with complete and incomplete data. Furthermore, there was no evidence of statistical heterogeneity between observed and imputed values and results from complete case analysis did not substantially differ from those based on MI (40 imputed datasets). A total of 158 measurement time points of children who did not have at least one valid PA measurement were excluded from analysis after imputation, resulting in a final sample of 498 children providing 952 observation time points (see Additional file 2 for a flow chart). Results presented in this work are based on imputed data, unless stated otherwise. No adjustments were made for multiple testing [34]. All analyses were performed using $\mathrm{R}$, version 3.2.3 ( $\mathrm{R}$ Foundation for Statistical Computing, Vienna, Austria). 


\section{Results}

Data for the current analysis are from the baseline (T0) and follow-up (T1) assessment of the SPLASHY study. Descriptive statistics of included participants $(n=498)$ are shown in Table 1. Mean age was 3.9 (0.7) and 4.9 (0.7) years at T0 and T1, respectively. All children at both time points fulfilled the recommendations of engaging in at least $180 \mathrm{~min}$ of PA per day. Children who participated at T1 and those lost to follow-up did not differ by age or sex.

TPA and MVPA increased with increasing age in both boys and girls (Table 2) with aggregated levels being significantly higher at 4,5 and 6 years compared to those observed at 3 years (aim 1 ).

Boys in the highest age category (6 years) accumulated 23\% more TPA and 37\% more MVPA and spent around the same amount of time sedentary as the youngest children (3 years). Likewise, girls in the highest age category accumulated 10\% more TPA and 20\% more MVPA and spent 5\% less time sedentary compared to the youngest. The relative increase of mean TPA levels was significant in both boys and girls from 3 to 4 years. From four to five only boys showed a further significant increase and from five to six the change was nonsignificant in both sexes. For MVPA the increase was significant in both boys and girls from 3 to 4 and 4 to 5 years, without any further significant increase occurring between 5 and 6 years. Time spent sedentary (around $6 \mathrm{~h}$ per day) remained reasonably stable over time with an average change of less than $2 \%$ comparing the oldest to the youngest age category.

To illustrate PA progression over time, observed values were plotted by age (Fig. 1). Trajectory profiles indicated that the difference between boys and girls gradually increased up to a difference of $115 \mathrm{cpm}(16 \%)$ in TPA and $27 \mathrm{~min} /$ day (24\%) in MVPA at age six.

Table 3 presents multivariate associations between potential determinants of TPA, MVPA and SB (aim 2).

All seven variables associated with TPA in the full multilevel analysis $(p \leq 0.1)$ were identified as determinants in the final model (all $p \leq 0.041$; Table 4). Boys were more active than girls and TPA was positively associated with age, gross motor skills and activity temperament. Children from single-parent families were more active than those living with two parents. For MVPA, five of a total of seven variables associated with the outcome in the full model were identified as determinants in the final model (all $p \leq 0.027$ ). Similar to TPA, boys spent more time moderately-to-vigorously active, MVPA increased with age, gross motor skills and activity temperament. Birth weight and parenting stress were also identified as determinants of both TPA and MVPA (positive association).

With SB as the outcome, results of the final model indicated that for two of four variables taken from the full model there was evidence for an association (all $p \leq 0.029)$ : activity temperament was negatively associated with SB and children were shown to be more sedentary in the spring and fall months compared to summer. The proportion of variance explained by the fixed factors (marginal $\mathrm{R}^{2}$ ) in the final models for TPA, MVPA and SB was $16 \%, 18 \%$ and $9 \%$, respectively. Including the random factors (conditional $\mathrm{R}^{2}$ ) resulted in $26 \%, 32 \%$ and $20 \%$ of variance explained in TPA, MVPA and SB. The increase in explained variance seen when adding the random factors was mainly attributable to the measurements nested within the child rather than the childcare center.

Although a number of factors were associated with levels of PA, as noted above, only one variable was shown to be associated with change in PA over time (aim 3; Table 5). Specifically, having an older sibling at baseline was associated with a difference in change of about $50 \mathrm{cpm}$ for TPA and $10 \mathrm{~min} /$ day for MVPA. None of the variables were associated with change in SB.

\section{Discussion}

The current study extends the extensive cross-sectional literature on preschoolers' activity behavior by examining longitudinal trajectories and associations of PA and SB in a representative preschool population. We found that PA increased over time in this active and healthy cohort with the increase being more pronounced in boys than girls. Non-modifiable individual-level variables had the greatest influence on PA levels; Sex and age were shown to be major determinants of TPA and MVPA and activity temperament was consistently strongly associated with all three outcomes. Gross motor skills were positively associated with both, TPA and MVPA, and family structure was shown to play a role in TPA, that is children of single parents were more active than those living in dual-parent families. The only determinant of change identified was older siblings, that is having one or more older siblings was associated with a greater positive change in TPA and MVPA. The complete set of variables in the final models of PA levels explained a considerable proportion of variance in TPA (28\%), MVPA (32\%) and SB (20\%) and would be associated with a total effect size of about $180 \mathrm{cpm}$ or $30 \mathrm{~min} /$ day MVPA. Thirty min of MVPA is half of what children are expected to do at age five or older. Although this is relevant from a guidelines perspective, we are only starting to understand the dose-response relationship of PA with health parameters in preschool children. Nevertheless, in a previous study an increase of $100 \mathrm{cpm}$ was found to be associated with a $2 \mathrm{mmHg}$ lower blood pressure in 5-to-7 year-old children [35]. This reduction was shown to result in a $6 \%$ reduction in coronary heart disease risk and a $15 \%$ reduction in the risk of stroke and transient ischemic attacks in adults [36]. Furthermore, an increment of 16 min MVPA over 1 year significantly 
Table 1 Participant characteristics and potential determinants of young children's objectively measured physical activity and sedentary behavior $(n=498)$

\begin{tabular}{|c|c|c|c|}
\hline & \multirow[b]{2}{*}{ Use in analysis } & \multicolumn{2}{|c|}{ Mean (SD) or percentages } \\
\hline & & T0 & $\mathrm{T1}$ \\
\hline \multicolumn{4}{|l|}{ Demographic and biological variables } \\
\hline Sex & $\%$ boys & 53.8 & 51.9 \\
\hline Age & years & $3.9(0.7)$ & $4.9(0.7)$ \\
\hline Birth weight & grams (per $100 \mathrm{~g}$ ) & $3290(570)$ & $3280(530)$ \\
\hline Chronic health condition & $\%$ with chronic health condition & 7.5 & 7.1 \\
\hline $\mathrm{BMI}^{\mathrm{a}}$ & $\%$ overweight or obese & 24.1 & 18.5 \\
\hline Gross motor skills ${ }^{\mathrm{a}}$ & Composite z-score & $0.0(1.0)$ & $0.1(1.1)$ \\
\hline Siblings & $\%$ having older siblings & 43.2 & 44.5 \\
\hline Parental BMI & $\%$ at least one overweight or obese parent & 52.2 & 52.5 \\
\hline SES & Range 16-90; increases with higher SES & $63.1(15.5)$ & $62.7(15.6)$ \\
\hline Family structure & $\%$ single parent households & 10.4 & 9.8 \\
\hline \multicolumn{4}{|l|}{ Psychological, cognitive and emotional variables } \\
\hline Self-regulation ${ }^{a}$ & Range 0-30; increases with better self-regulation & $19.2(9.5)$ & $23.3(8.0)$ \\
\hline Psychological difficulties & Range 0-40; increases with more difficulties & $8.8(4.3)$ & $8.5(4.7)$ \\
\hline Emotionality temperament & Range $1-5$; increases with more pronounced trait & $2.8(0.7)$ & $2.8(0.7)$ \\
\hline Activity temperament & Range $1-5$; increases with more pronounced trait & $3.8(0.7)$ & $3.7(0.7)$ \\
\hline Shyness temperament & Range $1-5$; increases with more pronounced trait & $2.4(0.7)$ & $2.4(0.7)$ \\
\hline Parenting stress & Range 5-90; increases with more parenting stress & $37.5(7.5)$ & $37.6(7.6)$ \\
\hline Cognitive performance $^{a}$ & Composite z-score & $0.0(1.0)$ & $0.1(0.9)$ \\
\hline \multicolumn{4}{|l|}{ Behavioral variables } \\
\hline Sleep duration & Hours & $10.8(0.6)$ & $10.8(0.5)$ \\
\hline Play frequency & $\%$ more than once/week & 91.2 & 93.1 \\
\hline \multicolumn{4}{|l|}{ Social and cultural variables } \\
\hline Parental sedentary behavior & Hours & $2.8[2.0,4.5]^{\mathrm{b}}$ & $3.0[2.0,5.0]^{\mathrm{b}}$ \\
\hline Parental sports club membership & $\%$ at least one parent is member & 32.0 & 32.8 \\
\hline Parental physical activity & $\%$ at least one parent is active & 63.4 & 61.6 \\
\hline Parental Involvement in child physical activity & $\%$ at least one parent is involved & 65.0 & 52.3 \\
\hline Mode of transport to childcare & $\%$ active & 40.7 & 48.1 \\
\hline Parental tobacco use & $\%$ at least one parent smokes & 24.1 & 24.4 \\
\hline Parental alcohol consumption & $\%$ at least one parent consumes large amounts & 5.5 & 4.5 \\
\hline \multicolumn{4}{|l|}{ Environmental variables } \\
\hline Time outdoors & Hours & $2.0[1.5,3.0]^{\mathrm{b}}$ & $2.0[1.5,3.0]^{\mathrm{b}}$ \\
\hline Fixed toys & Range 0-7 & $1.6(1.5)$ & $1.6(1.6)$ \\
\hline Portable toys & Range $0-8$ & $4.5(1.5)$ & $4.3(1.5)$ \\
\hline Days at childcare & Range 0-5 & $2.8(1.2)$ & $2.5(1.3)$ \\
\hline Living area per person & $m^{2}$ & $30.8(9.1)$ & $30.8(8.9)$ \\
\hline Neighborhood safety & Range 0-44; increases with increasing concerns & $12.6(7.0)$ & $12.4(7.2)$ \\
\hline Dog & $\%$ dog owner & 6.9 & 5.5 \\
\hline Season & $\%$ spring and fall months & 75.3 & 77.9 \\
\hline Region & $\%$ urban & 34.9 & 39.4 \\
\hline
\end{tabular}

PA physical activity, SB sedentary behavior, BMI body mass index, SES socio-economic status 
Table 2 Total physical activity (TPA), moderate-to-vigorous physical activity (MVPA) and sedentary behavior (SB) at each age category

\begin{tabular}{|c|c|c|c|c|}
\hline & 3 Years $^{a}$ & 4 Years $^{a}$ & 5 Years $^{a}$ & 6 Years $^{\mathrm{a}}$ \\
\hline$N_{\text {total }}\left(N_{\text {girls }}, N_{\text {boys }}\right)$ & $147(75,72)$ & $397(192,205)$ & $322(144,178)$ & $86(38,48)$ \\
\hline Number of valid days & $5.7(1.7)$ & $5.6(1.4)$ & $5.7(1.6)$ & $5.8(1.3)$ \\
\hline Monitor wear time [hours/day] & $12.7(0.7)$ & $12.8(0.8)$ & $12.9(0.8)$ & $13.0(0.8)$ \\
\hline \multicolumn{5}{|l|}{ TPA [cpm] } \\
\hline Boys & $595.2(138.4)$ & $654.9(160.3)$ & $681.5(148.5)$ & $731.1(167.3)$ \\
\hline Girls & $560.9(132.6)$ & $604.7(142.6)$ & $613.5(142.6)$ & $616.6(154.7)$ \\
\hline All & $577.8(136.2)$ & $631.3(154.1)$ & $651.6(149.5)$ & $683.3(170.7)$ \\
\hline \multicolumn{5}{|l|}{ MVPA [min/day] } \\
\hline Boys & $86.5(27.6)$ & $101.2(28.3)$ & $107.5(28.2)$ & $118.5(31.7)$ \\
\hline Girls & $76.1(25.3)$ & $85.7(25.4)$ & $90.3(26.6)$ & $91.4(23.0)$ \\
\hline All & $81.2(26.9)$ & $93.9(28.0)$ & $99.9(28.8)$ & $107.2(31.2)$ \\
\hline \multicolumn{5}{|l|}{ SB [min/day] } \\
\hline Boys & 370.7 (47.6) & $368.0(49.2)$ & 366.0 (45.9) & $370.3(50.4)$ \\
\hline Girls & $377.4(46.1)$ & $376.1(51.3)$ & $377.4(53.5)$ & $395.7(46.3)$ \\
\hline All & $374.1(46.8)$ & $371.8(50.3)$ & $371.0(49.6)$ & $380.9(50.0)$ \\
\hline
\end{tabular}

Aggregated data on the population level. Data are presented as mean (SD) except for $\mathrm{N}$

${ }^{a}$ Age categories are rounded to $+/-6$ months, e.g. 3 years corresponds to $2.5-3.5$ years

increased fitness, decreased body fat and improved cardiovascular health in schoolchildren [37].

The present study suggests that PA increases in young children. Two previous longitudinal studies also showed an increase in objectively measured physical activity over the preschool years $[10,11]$. Jackson DM, Reilly JJ, Kelly LA, Montgomery C, Grant S and Paton JY [10] reported that accelerometer-measured TPA increased by $27 \%$ in 603 -to-4 year-old Scottish children over 1 year. Examining the 24-month follow up in 42 children of the same study,

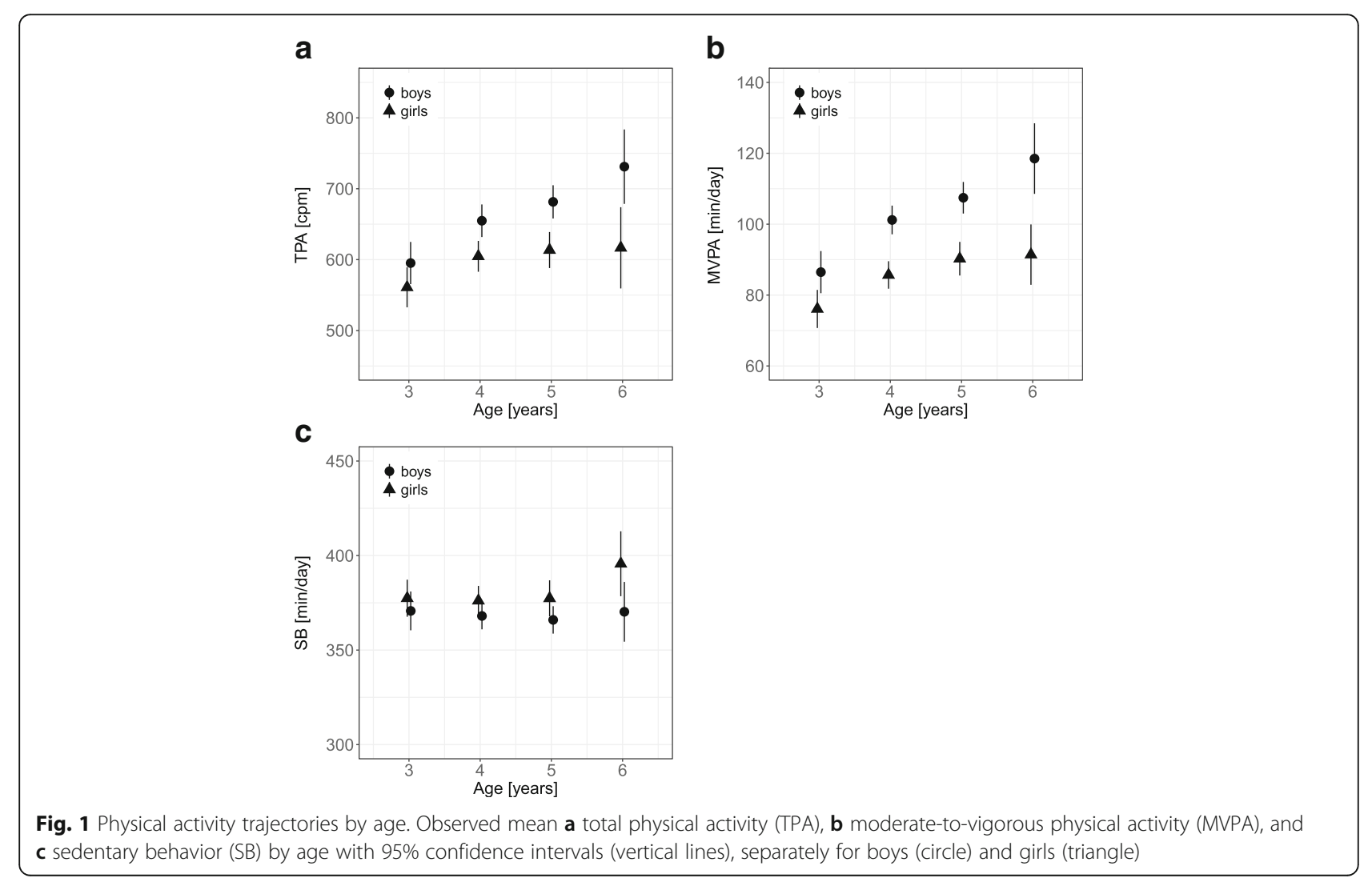


Table 3 Full models: associations of potential determinants with total physical activity (TPA), moderate-to-vigorous physical activity (MVPA) and sedentary behavior (SB) ${ }^{a}$

\begin{tabular}{|c|c|c|c|c|c|c|c|c|c|}
\hline & \multicolumn{3}{|c|}{ TPA [cpm] } & \multicolumn{3}{|c|}{ MVPA [min/day] } & \multicolumn{3}{|c|}{ SB [min/day] } \\
\hline & $\bar{\beta}$ & $95 \% \mathrm{Cl}$ & $p$-value & $\bar{\beta}$ & $95 \% \mathrm{Cl}$ & p-value & $\beta$ & $95 \% \mathrm{Cl}$ & p-value \\
\hline \multicolumn{10}{|l|}{ Demographic and biological variables } \\
\hline Sex & 46.7 & $(24.4,68.9)$ & $\leq 0.001$ & 14.4 & $(10.1$ 18.7) & $\leq 0.001$ & -5.1 & $(-13.1,2.8)$ & 0.208 \\
\hline Age & 32.5 & $(12.4,52.6)$ & 0.002 & 8.4 & $(4.6,12.1)$ & $\leq 0.001$ & 0.4 & $(-6.5,7.3)$ & 0.906 \\
\hline Birth weight & 2.2 & $(0.2,4.2)$ & 0.035 & 0.4 & $(0.1,0.8)$ & 0.030 & -0.6 & $(-1.4,0.1)$ & 0.077 \\
\hline Chronic health condition & 4.1 & $(-38.4,46.5)$ & 0.850 & 0.2 & $(-7.5,7.9)$ & 0.959 & -2.2 & $(-17.6,13.2)$ & 0.779 \\
\hline BMl & 9.8 & $(-16.0,35.6)$ & 0.457 & 2.7 & $(-2.0,7.5)$ & 0.261 & -5.1 & $(-14.6,4.3)$ & 0.286 \\
\hline Gross motor skills & 13.4 & $(2.1,24.7)$ & 0.021 & 2.9 & $(0.9,4.8)$ & 0.005 & -1.3 & $(-5.2,2.6)$ & 0.515 \\
\hline Siblings & 4.8 & $(-17.9,27.6)$ & 0.676 & 1.8 & $(-2.7,6.3)$ & 0.431 & -1.6 & $(-9.5,6.3)$ & 0.694 \\
\hline Parental BMI & -0.9 & $(-33.2,24.4)$ & 0.941 & 0.8 & $(-3.4,5.1)$ & 0.706 & -2.1 & $(-10.2,5.9)$ & 0.604 \\
\hline SES & 0.1 & $(-0.8,1)$ & 0.849 & 0.0 & $(-0.2,0.1)$ & 0.837 & -0.2 & $(-0.5,0.2)$ & 0.332 \\
\hline Family structure & 50.8 & $(6.1,95.6)$ & 0.027 & 6.2 & $(-2.1,14.5)$ & 0.142 & -17.3 & $(-33.7,-0.9)$ & 0.039 \\
\hline \multicolumn{10}{|c|}{ Psychological, cognitive and emotional variables } \\
\hline Self-regulation & -0.2 & $(-1.6,1.1)$ & 0.724 & 0.0 & $(-0.3,0.2)$ & 0.896 & 0.2 & $(-0.2,0.7)$ & 0.302 \\
\hline Psychological difficulties & 1.4 & $(-1.7,4.4)$ & 0.373 & 0.4 & $(-0.2,0.9)$ & 0.210 & -0.2 & $(-1.3,0.9)$ & 0.712 \\
\hline Emotionality temperament & -12.1 & $(-30.2,6.1)$ & 0.191 & -2.2 & $(-5.6,1.2)$ & 0.200 & 4.5 & $(-1.6,10.5)$ & 0.148 \\
\hline Activity temperament & 30.6 & $(12.7,48.5)$ & $\leq 0.001$ & 5.4 & $(1.9,8.9)$ & 0.002 & -11.8 & $(-18.3,-5.3)$ & $<0.001$ \\
\hline Shyness temperament & -10.4 & $(-26.9,6.2)$ & 0.218 & -1.5 & $(-4.6,1.5)$ & 0.317 & 1.4 & $(-4.2,7.1)$ & 0.623 \\
\hline Parenting stress & 2.0 & $(0.4,3.6)$ & 0.015 & 0.2 & $(-0.1,0.5)$ & 0.126 & -0.4 & $(-1.0,0.1)$ & 0.130 \\
\hline Cognitive performance & -0.6 & $(-12.3,11.1)$ & 0.916 & 0.7 & $(-1.4,2.9)$ & 0.501 & 0.8 & $(-3.4,5.0)$ & 0.714 \\
\hline \multicolumn{10}{|l|}{ Behavioral variables } \\
\hline Sleep duration & -5.3 & $(-24.6,13.9)$ & 0.585 & -1.1 & $(-4.6,2.4)$ & 0.614 & -1.7 & $(-8.2,4.8)$ & 0.599 \\
\hline Play frequency & -10.3 & $(-50.2,29.5)$ & 0.609 & -1.7 & $(-8.6,5.2)$ & 0.911 & 5.0 & $(-11.2,21.3)$ & 0.540 \\
\hline \multicolumn{10}{|l|}{ Social and cultural variables } \\
\hline Parental sedentary behavior & -0.1 & $(-3.8,3.7)$ & 0.976 & 0.1 & $(-0.6,0.8)$ & 0.791 & 0.2 & $(-1.1,1.5)$ & 0.800 \\
\hline Parental sports club membership & 10.2 & $(-14.1,34.4)$ & 0.410 & 0.4 & $(-4.0,4.8)$ & 0.854 & -4.5 & $(-13.0,4.1)$ & 0.307 \\
\hline Parental physical activity & -8.7 & $(-31.9,14.5)$ & 0.459 & -1.3 & $(-5.6,3.0)$ & 0.547 & -0.7 & $(-9.2,7.7)$ & 0.866 \\
\hline Parental Involvement in child PA & 8.0 & $(-14.1,30.1)$ & 0.477 & 1.3 & $(-2.8,5.4)$ & 0.535 & -2.7 & $(-10.6,5.2)$ & 0.496 \\
\hline Transport to childcare & 6.2 & $(-15.6,28.0)$ & 0.576 & 2.0 & $(-2.0,6.1)$ & 0.326 & -4.7 & $(-12.4,3.0)$ & 0.233 \\
\hline Parental tobacco use & -5.1 & $(-32.1,21.9)$ & 0.710 & -0.3 & $(-5.3,4.7)$ & 0.897 & 3.3 & $(-6.1,12.8)$ & 0.487 \\
\hline Parental alcohol consumption & 7.3 & $(-40.9,55.4)$ & 0.765 & 2.6 & $(-6.6,11.8)$ & 0.580 & -8.0 & $(-26.9,10.9)$ & 0.402 \\
\hline \multicolumn{10}{|l|}{ Environmental variables } \\
\hline Time outdoors & 4.6 & $(-2.6,11.8)$ & 0.205 & 0.2 & $(-1.1,1.5)$ & 0.807 & -1.4 & $(-3.9,1.0)$ & 0.247 \\
\hline Fixed toys & 3.8 & $(-3.7,11.3)$ & 0.318 & 0.1 & $(-1.3,1.5)$ & 0.907 & -0.5 & $(-3.2,2.2)$ & 0.713 \\
\hline Portable toys & 4.8 & $(-3.5,13.2)$ & 0.253 & 0.7 & $(-0.7,2.2)$ & 0.339 & -2.6 & $(-5.4,0.2)$ & 0.067 \\
\hline Days at childcare & 1.8 & $(-9.6,13.2)$ & 0.751 & -0.1 & $(-2.1,1.9)$ & 0.924 & 0.7 & $(-3.3,4.8)$ & 0.726 \\
\hline Living area per person & 0.6 & $(-0.8,2.0)$ & 0.415 & 0.1 & $(-0.2,0.4)$ & 0.432 & 0.0 & $(-0.5,0.5)$ & 0.911 \\
\hline Neighborhood safety & -0.9 & $(-2.8,0.9)$ & 0.330 & -0.1 & $(-0.5,0.2)$ & 0.481 & 0.1 & $(-0.5,0.8)$ & 0.730 \\
\hline Dog & 0.5 & $(-42.5,43.6)$ & 0.980 & -0.8 & $(-8.7,7.2)$ & 0.853 & -1.3 & $(-16.4,13.8)$ & 0.864 \\
\hline Season & 4.1 & $(-22.2,30.5)$ & 0.758 & 4.1 & $(-0.9,9.0)$ & 0.106 & 9.1 & $(-0.8,18.9)$ & 0.071 \\
\hline Region & 1.7 & $(-23.4,26.8)$ & 0.892 & 0.5 & $(-4.3,5.2)$ & 0.852 & -1.3 & $(-10.4,7.8)$ & 0.782 \\
\hline
\end{tabular}

PA physical activity, $\beta \beta$-coefficient, $C l$ confidence interval 
Table 4 Final models: associations of determinants with total physical activity (TPA), moderate-to-vigorous physical activity (MVPA) and sedentary behavior $(\mathrm{SB})^{\mathrm{a}}$

\begin{tabular}{|c|c|c|c|c|c|c|c|c|c|}
\hline & \multicolumn{3}{|c|}{ TPA [cpm] } & \multicolumn{3}{|c|}{ MVPA [min/day] } & \multicolumn{3}{|c|}{ SB [min/day] } \\
\hline & $\beta$ & $95 \% \mathrm{Cl}$ & $p$-value & $\beta$ & $95 \% \mathrm{Cl}$ & $p$-value & $\beta$ & $95 \% \mathrm{Cl}$ & $p$-value \\
\hline \multicolumn{10}{|c|}{ Demographic and biological variables } \\
\hline Sex & 49.8 & $(28.5,71.2)$ & $\leq 0.001$ & 14.8 & $(10.7,19.0)$ & $\leq 0.001$ & -7.1 & $(-14.4,0.3)$ & 0.062 \\
\hline Age & 31.6 & $(17.6,45.6)$ & $\leq 0.001$ & 8.9 & $(6.0,11.8)$ & $\leq 0.001$ & - & - & - \\
\hline Birth weight & 2.3 & $(0.4,4.2)$ & 0.018 & 0.4 & $(0.1,0.8)$ & 0.027 & - & - & - \\
\hline Gross motor skills & 10.7 & $(0.1,21.3)$ & 0.048 & 2.2 & $(0.4,4.2)$ & 0.023 & - & - & - \\
\hline Family structure & 59.3 & $(11.7,106.8)$ & 0.016 & - & - & - & -20.1 & $(-46.0,5.7)$ & 0.123 \\
\hline \multicolumn{10}{|c|}{ Psychological, cognitive and emotional variables } \\
\hline Activity temperament & 39.2 & $(23.2,55.2)$ & $\leq 0.001$ & 6.4 & $(3.1,9.6)$ & $\leq 0.001$ & -12.8 & $(-19.1,-6.5)$ & $\leq 0.001$ \\
\hline Parenting stress & 1.8 & $(0.3,3.2)$ & 0.017 & 0.2 & $(-0.1,0.5)$ & 0.123 & - & - & - \\
\hline \multicolumn{10}{|l|}{ Environmental variables } \\
\hline Season & - & - & - & 2.6 & $(-2.8,7.9)$ & 0.344 & 11.9 & $(1.2,22.6)$ & 0.029 \\
\hline
\end{tabular}

$\beta \beta$-coefficient, $\mathrm{Cl}$ confidence interval

${ }^{a}$ Multivariable linear mixed models including a random intercept for each subject and for each childcare center showing all variables with $P \leq 0.1$ of the respective full model $(n=498)$

Kelly LA, Reilly JJ, Jackson DM, Montgomery C, Grant S and Paton JY [11] found a $22 \%$ increase in activity from baseline. In contrast, a prospective study of 208 preschool aged children in New Zealand found a decline of about $40 \%$ in overall and $50 \%$ in MVPA in both sexes from age three to age four, without a significant further decline between 4 and 5 years [12]. The variation in results is difficult to explain. Children participating in the aforementioned studies [10-12] were subject to a comparable educational system as children in our study. Since the transition from preschool to primary school is commonly thought to have a marked impact on PA behavior [38], we did not mention studies that included children who had entered formal schooling at follow-up. The contradicting findings, however, may arise from methodological discrepancies in PA data collection and processing such as the use of different devices and intensity thresholds leading to comparability issues, or variation in adjustment for confounders [23]. Our study is the largest prospective study examining longitudinal trajectories of PA and SB and we applied the most rigorous accelerometer validity criteria [39]. In addition, the explanatory power of our models was relatively high, ranging from 26 to $32 \%$. Since wear-time did not differ significantly between the age categories and was shown to be unrelated to activity intensities, the increase in PA found in our study was not attributable to the slightly longer wear-time in older children. Rather, a plausible explanation that has been reinforced by relevant existing literature is that advancing motor proficiency in this age group contributes to an increase in PA levels [40-42].

Our results further illustrate that sex differences in physical activity already occur from a young age. We found boys to consistently engage in more TPA and MVPA than girls at all ages during the preschool years, a pattern commonly described in later childhood and adolescence. While TPA and MVPA increased over time in both sexes, the difference in activity levels between the sexes was lowest for the youngest children and with a difference of $16 \%(115 \mathrm{cpm})$ for TPA and of $24 \%$ (27 $\mathrm{min} /$ day) for MVPA highest in the oldest. There is strong evidence from cross-sectional and longitudinal studies pointing towards a sex difference in activity levels at the preschool age [5, 43-46]. Currently, there is no conclusive explanation as to why girls are less physically active than boys and whether these lower levels are a health concern. In fact, considering that overall females have higher health status than men in spite of being less physically active than their male peers throughout the life span [47], it is questionable whether the "one-size-fits-all" approach is appropriate for meaningful and beneficial PA. Males and females may be predisposed to engage in different levels of intensity and type of activity [48]. It is plausible to assume that biological differences, such as patterns of development and maturation and differences in physiology and body composition, may contribute to sex differences in PA. Thus, before we continue targeting females with the aim of increasing PA to recommended standards, a clear understanding of whether and how PA provides health benefits differently for males and females and how findings may translate to policy and practice has to be established.

We further found a strong and consistent association between the child's activity temperament and objectively measured TPA, MVPA and SB in both boys and girls. Parents reported their children's temperamental 
Table 5 Change models: associations of potential determinants with changes in total physical activity (TPA), moderate-to-vigorous physical activity (MVPA) and sedentary behavior (SB) ${ }^{\mathrm{a}}$

\begin{tabular}{|c|c|c|c|c|c|c|c|c|c|}
\hline & \multicolumn{3}{|c|}{ TPA [cpm] } & \multicolumn{3}{|c|}{ MVPA [min/day] } & \multicolumn{3}{|c|}{ SB [min/day] } \\
\hline & $\beta$ & $95 \% \mathrm{Cl}$ & $p$-value & $\beta$ & $95 \% \mathrm{Cl}$ & $p$-value & $\beta$ & $95 \% \mathrm{Cl}$ & p-value \\
\hline \multicolumn{10}{|l|}{ Demographic and biological variables } \\
\hline Sex & 22.2 & $(-13.2,57.7)$ & 0.218 & 4.4 & $(-2.3,11.1)$ & 0.195 & -8.0 & $(-21.2,5.2)$ & 0.238 \\
\hline Age & -28.4 & $(-66.2,9.3)$ & 0.139 & -5.6 & $(-12.3,1.2)$ & 0.108 & -3.9 & $(-17.59 .7)$ & 0.571 \\
\hline Birth weight & 0.4 & $(-3.1,3.9)$ & 0.817 & 0.0 & $(-0.6,0.6)$ & 0.996 & -0.3 & $(-1.4,0.9)$ & 0.660 \\
\hline Chronic health condition & 2.9 & $(-67.4,73.2)$ & 0.936 & 2.2 & $(-10.2,14.7)$ & 0.726 & -4.6 & $(-30.7,21.4)$ & 0.726 \\
\hline $\mathrm{BMI}$ & -26.5 & $(-68.9,15.9)$ & 0.220 & -3.9 & $(-11.4,3.5)$ & 0.303 & 4.1 & $(-12.2,20.3)$ & 0.622 \\
\hline Gross motor skills & -16.8 & $(-37.6,3.9)$ & 0.111 & -3.0 & $(-6.6,0.6)$ & 0.111 & 5.3 & $(-1.7,12.3)$ & 0.142 \\
\hline Siblings & 50.5 & $(12.4,88.6)$ & 0.010 & 10.1 & $(3.1,17.0)$ & 0.004 & -8.2 & $(-23.3,6.9)$ & 0.287 \\
\hline Parental BMI & -11.0 & $(-48.6,26.6)$ & 0.566 & -3.0 & $(-9.7,3.7)$ & 0.389 & 6.2 & $(-8.2,20.6)$ & 0.395 \\
\hline SES & 0.0 & $(-1.3,1.4)$ & 0.969 & 0.0 & $(-0.2,0.2)$ & 0.792 & 0.0 & $(-0.5,0.4)$ & 0.858 \\
\hline Family structure & -7.3 & $(-79.9,65.3)$ & 0.842 & -1.1 & $(-13.6,11.4)$ & 0.864 & 17.8 & $(-6.9,42.6)$ & 0.158 \\
\hline \multicolumn{10}{|c|}{ Psychological, cognitive and emotional variables } \\
\hline Self-regulation & 0.4 & $(-1.8,2.6)$ & 0.735 & 0.1 & $(-0.3,0.4)$ & 0.683 & 0.1 & $(-0.7,0.87)$ & 0.833 \\
\hline Psychological difficulties & -4.4 & $(-9.7,0.9)$ & 0.105 & -0.9 & $(-1.8,0.1)$ & 0.076 & 0.5 & $(-1.4,2.5)$ & 0.587 \\
\hline Emotionality temperament & 11.1 & $(-21.2,43.4)$ & 0.497 & 2.1 & $(-3.7,7.9)$ & 0.480 & -3.3 & $(-15.1,8.6)$ & 0.588 \\
\hline Activity temperament & -8.0 & $(-39.1,23.1)$ & 0.612 & -0.1 & $(-5.8,5.6)$ & 0.976 & 6.8 & $(-4.1,17.8)$ & 0.221 \\
\hline Shyness temperament & 0.5 & $(-28.2,29.2)$ & 0.974 & 0.4 & $(-4.7,5.4)$ & 0.880 & 2.2 & $(-7.9,12.2)$ & 0.672 \\
\hline Parenting stress & -0.5 & $(-3.2,2.2)$ & 0.719 & -0.1 & $(-0.5,0.4)$ & 0.742 & 0.1 & $(-0.9,1.1)$ & 0.828 \\
\hline Cognitive performance & -4.7 & $(-24.1,14.7)$ & 0.637 & -2.2 & $(-5.6,1.2)$ & 0.203 & -0.7 & $(-7.6,6.2)$ & 0.842 \\
\hline \multicolumn{10}{|l|}{ Behavioral variables } \\
\hline Sleep duration & -3.0 & $(-34.7,28.7)$ & 0.853 & 0.1 & $(-5.5,5.6)$ & 0.984 & 4.7 & $(-5.6,14.9)$ & 0.375 \\
\hline Play frequency & 53.5 & $(-10.9,117.8)$ & 0.103 & 7.2 & $(-4.2,18.6)$ & 0.216 & -11.9 & $(-36.4,12.5)$ & 0.337 \\
\hline \multicolumn{10}{|l|}{ Social and cultural variables } \\
\hline Parental sedentary behavior & -0.9 & $(-6.9,5.1)$ & 0.761 & -0.2 & $(-1.3,0.8)$ & 0.670 & 0.5 & $(-1.7,2.7)$ & 0.683 \\
\hline Parental sports club membership & 3.9 & $(-41.3,49.1)$ & 0.866 & 2.6 & $(-5.5,10.7)$ & 0.531 & 7.3 & $(-9.0,23.6)$ & 0.376 \\
\hline Parental physical activity & -6.8 & $(-47.3,33.8)$ & 0.743 & -0.5 & $(-7.7,6.7)$ & 0.898 & 3.5 & $(-11.1,18.2)$ & 0.637 \\
\hline Parental Involvement in child PA & -9.8 & $(-51.3,31.7)$ & 0.643 & -2.9 & $(-9.9,4.2)$ & 0.428 & 0.3 & $(-15.3,15.9)$ & 0.968 \\
\hline Transport to childcare & -0.5 & $(-39.5,38.6)$ & 0.981 & -0.7 & $(-7.6,6.1)$ & 0.836 & 3.7 & $(-10.4,17.8)$ & 0.610 \\
\hline Parental tobacco use & -4.0 & $(-48.2,40.2)$ & 0.859 & -0.5 & $(-8.5,7.5)$ & 0.902 & 1.7 & $(-15.8,19.1)$ & 0.853 \\
\hline Parental alcohol consumption & -12.9 & $(-98.2,72.3)$ & 0.764 & -3.6 & $(-18.4,11.1)$ & 0.627 & 8.4 & $(-22.9,39.6)$ & 0.598 \\
\hline \multicolumn{10}{|l|}{ Environmental variables } \\
\hline Time outdoors & -8.1 & $(-21.5,5.2)$ & 0.233 & -0.5 & $(-2.93,1.9)$ & 0.705 & 2.4 & $(-2.5,7.3)$ & 0.335 \\
\hline Fixed toys & -5.8 & $(-19.2,7.5)$ & 0.392 & -0.6 & $(-3.0,1.7)$ & 0.613 & 0.6 & $(-4.4,5.5)$ & 0.827 \\
\hline Portable toys & 3.5 & $(-11.8,18.9)$ & 0.651 & 0.5 & $(-2.2,3.3)$ & 0.695 & -1.6 & $(-7.2,4.0)$ & 0.574 \\
\hline Days at childcare & 0.7 & $(-17.8,19.1)$ & 0.944 & 0.2 & $(-3.1,3.4)$ & 0.919 & -0.4 & $(-7.0,6.2)$ & 0.907 \\
\hline Living area per person & 0.8 & $(-1.5,3.1)$ & 0.519 & 0.1 & $(-0.3,0.4)$ & 0.791 & -0.4 & $(-1.3,0.4)$ & 0.331 \\
\hline Neighborhood safety & 1.2 & $(-1.6,4.1)$ & 0.402 & 0.1 & $(-0.4,0.6)$ & 0.691 & -0.1 & $(-1.1,1.0)$ & 0.921 \\
\hline Dog & 15.6 & $(-55.2,86.4)$ & 0.664 & 3.6 & $(-9.4,16.6)$ & 0.584 & -6.4 & $(-32.9,20.2)$ & 0.637 \\
\hline Season & -31.1 & $(-76.4,14.3)$ & 0.178 & -4.0 & $(-12.4,4.5)$ & 0.356 & 3.7 & $(-12.6,20.0)$ & 0.657 \\
\hline Region & 1.1 & $(-43.7,46.0)$ & 0.961 & 0.3 & $(-7.9,8.6)$ & 0.938 & -5.8 & $(-21.3,9.7)$ & 0.461 \\
\hline
\end{tabular}

PA physical activity, $\beta$-coefficient, $C l$ confidence interval 
characteristics using the Emotionality, Activity, and Sociability Temperament Survey (EAS) [49] at baseline and follow-up. Of all four dimensions used to conceptualize temperament (emotionality, activity, and sociability and shyness), only the activity dimension emerged as a predictor of PA and SB. Activity temperament refers to an individual's preferred level of activity and speed of action. As temperamental traits reflect generalized tendencies rather than motivation or abilities and are believed to change little over time [50,51], a young child's temperamental activity may influence lifelong PA with potential implications for disease risk. Examining the activity temperament may reveal important pre-dispositions for PA and help identify high-risk individuals. Moreover, an understanding of the underlying processes and relationships that link temperament with the development of PA patterns may provide important insights for PA promotion. The role of childhood temperament in shaping activity behavior is still largely unexplored. One previous cross-sectional study concluded that none of the six domains of temperament, including activity, assessed by the Child Temperament Questionnaire (CTQ) was associated with objectively measured PA and SB in preschoolers [52] whereas a recent publication found that early childhood temperamental activity level predicted self-reported adolescent PA in males [53].

Consistent and robust evidence about what elements effect positive change in young children's PA is lacking to date and limited attention has been given to the impact of siblings. However, as children spend a large amount of time in the home environment, it is important to consider sibling influence. Evidence from crosssectional studies suggests a positive association between the presence of older siblings in the household and children's MVPA [54]. A recently published systematic review of qualitative literature concluded that siblings were perceived to both facilitate and inhibit young children's physical activity levels [55]. On the one hand, preschool aged children often want to mimic or play with their older siblings and siblings may take pressure off parents by providing other children with whom the young child can be active $[55,56]$. On the other hand, siblings were found to have no influence on or even be a barrier for preschoolers' PA because having more than one child may pose challenges to facilitating organized PA or finding activities suitable for children at varying developmental stages [55-57]. While most studies considered the influence of siblings in general, a recent qualitative study in preschool children showed that specifically older siblings tended to influence the younger more often and that particularly home-based PA was positively affected (unless older siblings inspired the younger to participate in structured PA) [57]. Among the scarce quantitative evidence investigating determinants of change in young children's PA [21], the only prospective study examining sibling influence found that sibling co-participation in PA but not sibling PA levels was positively associated with change in MVPA among five- to six-year-olds [58]. Our findings suggest that siblings play an important role in shaping their younger's activity behavior by inducing a positive change in TPA and MVPA, irrespective of the absolute levels. Interventions aimed at increasing PA levels among young children may have a greater likelihood of success if the potential of sibling influence is considered/included. Increasing parental awareness of free, informal and spontaneous opportunities in home-based settings, e.g. in the garden or neighborhood, may help support the influence of siblings. This is particularly important, as parents of young children are central to facilitating or restricting much of their child's interaction with the environment, such as the interaction with siblings and peers. Moreover, special emphasis should be placed on firstborns and only-children. In the case where older siblings are not available, interventions may focus on providing opportunities for companionship or playmates to substitute sibling encouragement and role modeling. For instance, children without older siblings from different families may be paired to promote their PA. Further exploration of the unique influence of siblings and friends is required.

Key strengths of the present study include the longitudinal design, which allows for drawing more robust conclusions about the direction of associations and changes over time, the comprehensive assessment of numerous objective measures and parent-report data, the use of objective, reliable, and validated measures of PA, the examination of an extended set of potential determinants guided by the socio-ecological model, and the large and representative sample of preschool children. Our study has several limitations. The relatively short followup period of 12 months is one of our key limitations. In addition, accelerometers were removed during aquatic activities likely resulting in an underestimation of PA, and parent-reported data used in this study might have been biased by memory and expectations. Although the proportion of variance explained based on the final models indicate a good performance of the set of exposure variables, particularly for TPA and MVPA, additional factors not considered in this work may have a substantial influence on activity levels in young children. Such factors include, amongst others, genetic traits, variables related to different contexts, policies and practices (e.g. the care environment) and site-specific objectively measured physical environmental properties. Finally, the generalizability of our findings may be reduced because our sample was recruited from children attending childcare on a regular basis and we cannot rule out the possibility that some of the associations observed are chance findings. 


\section{Conclusions}

In our sample of typically developing preschool children, PA increased over time with boys being consistently more active than girls. Among a large set of diverse potential determinants, individual-level factors had the greatest influence on activity behavior; age, sex and activity temperament were most relevant to determining activity levels, and the existence of older siblings was found to induce positive change in these levels. Despite enormous efforts, research has failed to identify modifiable determinants of physical activity that can be used to inform physical activity promotion. We therefore suggest that future research should attempt to broaden our understanding of how young children's sufficient PA levels can be maintained following the preschool years. We urgently need good-quality longitudinal studies that cover the entire range of childhood development including important factors such as educational and migrational transitions, social networks and epigenetics.

\section{Additional files}

Additional file 1: Potential determinants. Detailed description of all potential determinants. (PDF $146 \mathrm{~kb}$ )

Additional file 2: Flow chart. Diagram describing the inclusion of participants in the present study. (PDF $54 \mathrm{~kb}$ )

\section{Abbreviations}

BMl: Body mass index; cpm: counts per minute; EAS: Emotionality, activity, and sociability temperament survey; ISEI: International socio-economic index; MI: Multiple imputation; min: Minute; MVPA: Moderate-to-vigorous physical activity; OECD: The Organization for Economic Co-operation and Development; PA: Physical activity; SB: Sedentary behavior; SD: Standard deviation; SES: Socio-economic status; TPA: Total physical activity; WHO: World Health Organization

\section{Acknowledgements}

We thank the children and parents who gave us their time and a team of dedicated study staff for their assistance in data collection.

\section{Funding}

The study was funded by the Swiss National Science Foundation (CRSII3_147673) and the Jacobs Foundation.

\section{Availability of data and materials}

The dataset supporting the conclusions of this article is available upon reasonable request to the corresponding author.

\footnotetext{
Authors' contributions

Conceived and designed the SPLASHY study: JJP, SK, SM, OGJ. Performed data collection: EAS, CLA, AEZ, THK, KS, NMB, AA. Designed the research, had full access to all data, and take responsibility for the integrity of data and accuracy of data analysis: EAS, SK. Assisted in statistical data analysis: SH, AM. Performed data analysis and wrote, reviewed, and edited the manuscript: EAS. All authors reviewed, edited and approved the manuscript.
}

\section{Ethics approval and consent to participate}

Ethical approval was obtained from all local ethical committees (No. 338/13 for the Ethical Committee of the Canton of Vaud as the main ethical committee), children provided oral consent and parents provided written informed consent for their participating child.

\section{Consent for publication}

Not applicable.

\section{Competing interests}

The authors declare that they have no competing interests.

\section{Publisher's Note}

Springer Nature remains neutral with regard to jurisdictional claims in published maps and institutional affiliations.

\section{Author details}

${ }^{1}$ Epidemiology, Biostatistics and Prevention Institute, University of Zurich, Hirschengraben 84, 8001 Zurich, Switzerland. ${ }^{2}$ Child Development Center, University Children's Hospital Zurich, Steinwiesstrasse 75, 8032 Zurich, Switzerland. ${ }^{3}$ Department of Clinical Psychology and Psychotherapy, University of Fribourg, Clinical Psychology and Psychotherapy, Rue P.A. de Faucigny 2, 1700 Fribourg, Switzerland. ${ }^{4}$ Endocrinology, Diabetes \& Metabolism Service, Centre Hospitalier Universitaire Vaudois (CHUV), Avenue Pierre Decker 2, 1011 Lausanne, Switzerland. ${ }^{5}$ Department of Psychology, University of Basel, Missionsstrasse 62A, 4055 Basel, Switzerland. ${ }^{6}$ Division of Pediatric Endocrinology, Diabetology and Obesity, Centre Hospitalier Universitaire Vaudois (CHUV), Rue du Bugnon 46, 1011 Lausanne, Switzerland. ${ }^{7}$ Children's Research Center, University Children's Hospital Zurich, Steinwiesstrasse 75, 8032 Zurich, Switzerland.

Received: 21 November 2017 Accepted: 27 March 2018

Published online: 04 April 2018

\section{References}

1. Timmons BW, Leblanc AG, Carson V, Connor Gorber S, Dillman C, Janssen I, Kho ME, Spence JC, Stearns JA, Tremblay MS. Systematic review of physical activity and health in the early years (aged 0-4 years). Appl Physiol Nutr Metab. 2012;37:773-92.

2. Canadian Society for Exercise Physiology. Canadian physical activity guidelines. Ottawa: The Canadian Society for Exercise Physiology; 2012.

3. Department of Health, Physical Activity, Health Improvement and Protection. Start active, stay active: a report on physical activity from the four home countries' chief medical officers. London: Department of Health, Physical Activity, Health Improvement and Protection; 2011.

4. Department of Health and Aging, Australia. Get up and grow: healthy eating and physical activity for early childhood. Canberra: Australian Government; 2009.

5. Vale S, Silva P, Santos R, Soares-Miranda L, Mota J. Compliance with physical activity guidelines in preschool children. J Sports Sci. 2010;28:603-8.

6. Schmutz EA, Leeger-Aschmann CS, Radtke T, Muff S, Kakebeeke TH, Zysset AE, Messerli-Burgy N, Stulb K, Arhab A, Meyer AH, et al. Correlates of preschool children's objectively measured physical activity and sedentary behavior: a cross-sectional analysis of the SPLASHY study. Int J Behav Nutr Phys Act. 2017;14:1.

7. Hesketh KR, McMinn AM, Ekelund U, Sharp SJ, Collings PJ, Harvey NC, Godfrey KM, Inskip HM, Cooper C, van Sluijs EM. Objectively measured physical activity in four-year-old British children: a cross-sectional analysis of activity patterns segmented across the day. Int J Behav Nutr Phys Act. 2014;11:1.

8. Hinkley T, Salmon J, Okely AD, Crawford D, Hesketh K. Preschoolers' physical activity, screen time, and compliance with recommendations. Med Sci Sports Exerc. 2012;44:458-65.

9. Reilly JJ, Jackson DM, Montgomery C, Kelly LA, Slater C, Grant S, Paton JY. Total energy expenditure and physical activity in young Scottish children: mixed longitudinal study. Lancet. 2004;363:211-2.

10. Jackson DM, Reilly JJ, Kelly LA, Montgomery C, Grant S, Paton JY. Objectively measured physical activity in a representative sample of 3- to 4-year-old children. Obes Res. 2003;11:420-5.

11. Kelly LA, Reilly JJ, Jackson DM, Montgomery C, Grant S, Paton JY. Tracking physical activity and sedentary behavior in young children. Pediatr Exerc Sci. 2007;19:51-60.

12. Taylor RW, Murdoch L, Carter P, Gerrard DF, Williams SM, Taylor BJ. Longitudinal study of physical activity and inactivity in preschoolers: the FLAME study. Med Sci Sports Exerc. 2009;41:96-102.

13. Jones RA, Hinkley T, Okely AD, Salmon J. Tracking physical activity and sedentary behavior in childhood: a systematic review. Am J Prev Med. 2013:44:651-8. 
14. Hinkley T, Teychenne M, Downing KL, Ball K, Salmon J, Hesketh KD. Early childhood physical activity, sedentary behaviors and psychosocial wellbeing: a systematic review. Prev Med. 2014;62:182-92.

15. Sallis JF, Owen N, Fisher EB. Ecological models of health behavior. In: Glanz K, Rimer B, Viswanath K, editors. Health behavior and health education: theory, research, and practice. 4th ed. San Francisco: JosseyBass; 2008. p. 464-85.

16. Bingham DD, Costa S, Hinkley T, Shire KA, Clemes SA, Barber SE. Physical activity during the early years: a systematic review of correlates and determinants. Am J Prev Med. 2016;51:384-402.

17. Finch M, Jones J, Yoong S, Wiggers J, Wolfenden L. Effectiveness of Centrebased childcare interventions in increasing child physical activity: a systematic review and meta-analysis for policymakers and practitioners. Obes Rev. 2016;17:412-28.

18. Atkin AJ, van Sluijs EMF, Dollman J, Taylor WC, Stanley RM. Identifying correlates and determinants of physical activity in youth: how can we advance the field? Prev Med. 2016;87:167-9.

19. Brug J, Chinapaw M. Determinants of engaging in sedentary behavior across the lifespan; lessons learned from two systematic reviews conducted within DEDIPAC. Int J Behav Nutr Phys Act. 2015;12:134.

20. Stierlin AS, De Lepeleere S, Cardon G, Dargent-Molina P, Hoffmann B, Murphy MH, Kennedy A, O'Donoghue G, Chastin SF, De Craemer M, consortium D. A systematic review of determinants of sedentary behaviour in youth: a DEDIPAC-study. Int J Behav Nutr Phys Act. 2015;12:133.

21. Hesketh KR, O'Malley C, Paes VM, Moore H, Summerbell C, Ong KK, Lakshman R, van Sluijs EMF. Determinants of change in physical activity in children 0-6 years of age: a systematic review of quantitative literature. Sports Med. 2017;47:1349-74.

22. Messerli-Bürgy N, Kakebeeke TH, Arhab A, Stülb K, Zysset EA, LeegerAschmann CS, Schmutz EA, Fares F, Meyer HA, Munsch S, et al. The Swiss preschoolers' health study (SPLASHY): objectives and design of a prospective multi-site cohort study assessing psychological and physiological health in young children. BMC Pediatr. 2016;16:1-16.

23. Cliff DP, Reilly JJ, Okely AD. Methodological considerations in using accelerometers to assess habitual physical activity in children aged 0-5 years. J Sci Med Sport. 2009;12:557-67.

24. Janssen X, Cliff DP, Reilly JJ, Hinkley T, Jones RA, Batterham M, Ekelund U, Brage S, Okely AD. Predictive validity and classification accuracy of ActiGraph energy expenditure equations and cut-points in young children. PLoS One. 2013;8:e79124.

25. Pate RR, Almeida MJ, Mclver KL, Pfeiffer KA, Dowda M. Validation and calibration of an accelerometer in preschool children. Obesity (Silver Spring). 2006;14:2000-6

26. Evenson KR, Catellier DJ, Gill K, Ondrak KS, McMurray RG. Calibration of two objective measures of physical activity for children. J Sports Sci. 2008;26:1557-65.

27. Bauman AE, Sallis JF, Dzewaltowski DA, Owen N. Toward a better understanding of the influences on physical activity: the role of determinants, correlates, causal variables, mediators, moderators, and confounders. Am J Prev Med. 2002;23:5-14.

28. Tu YK, Gilthorpe MS. Revisiting the relation between change and initial value: a review and evaluation. Stat Med. 2007;26:3205-6.

29. Nakagawa S, Schielzeth $\mathrm{H}$. A general and simple method for obtaining R2 from generalized linear mixed-effects models. Methods Ecol Evol. 2013;4:133-42.

30. van Buuren S, Groothuis-Oudshoorn K. Mice: multivariate imputation by chained equations in R. J Stat Softw. 2011;45(3):1-67. http://www.jstatsoft.org/v45/i03/.

31. White IR, Carlin JB. Bias and efficiency of multiple imputation compared with complete-case analysis for missing covariate values. Stat Med. 2010;29: 2920-31.

32. Graham JW. Missing data analysis: making it work in the real world. Annu Rev Psychol. 2009;60:549-76.

33. White IR, Royston P, Wood AM. Multiple imputation using chained equations: issues and guidance for practice. Stat Med. 2011;30:377-99.

34. Althouse AD. Adjust for multiple comparisons? It's not that simple. Ann Thorac Surg. 2016;101:1644-5.

35. Knowles G, Pallan M, Thomas GN, Ekelund U, Cheng KK, Barrett T, Adab P. Physical activity and blood pressure in primary school children: a longitudinal study. Hypertension. 2013;61:70-5

36. Cook NR, Cohen J, Hebert PR, Taylor JO, Hennekens CH. Implications of small reductions in diastolic blood pressure for primary prevention. Arch Intern Med. 1995;155:701-9.
37. Kriemler S, Zahner L, Schindler C, Meyer U, Hartmann T, Hebestreit H, Brunner-La Rocca HP, van Mechelen W, Puder JJ. Effect of school based physical activity programme (KISS) on fitness and adiposity in primary schoolchildren: cluster randomised controlled trial. BMJ. 2010;340:c785.

38. Cooper AR, Goodman A, Page AS, Sherar LB, Esliger DW, van Sluijs EMF, Andersen LB, Anderssen S, Cardon G, Davey R, et al. Objectively measured physical activity and sedentary time in youth: the international children's accelerometry database (ICAD). Int J Behav Nutr Phys Act. 2015;12:113.

39. Migueles JH, Cadenas-Sanchez C, Ekelund U, Nystrom CD, Mora-Gonzalez J, Lof M, Labayen I, Ruiz JR, Ortega FB. Accelerometer data collection and processing criteria to assess physical activity and other outcomes: a systematic review and practical considerations. Sports Med. 2017;47:1821-45.

40. Robinson LE. The relationship between perceived physical competence and fundamental motor skills in preschool children. Child Care Health Dev. 2011; 37:589-96.

41. Stodden DF, Goodway JD, Langendorfer SJ, Roberton MA, Rudisill ME, Garcia C, Garcia LE. A developmental perspective on the role of motor skill competence in physical activity: an emergent relationship. Quest. 2008;60:290-306.

42. Wick K, Leeger-Aschmann CS, Monn ND, Radtke T, Ott LV, Rebholz CE, Cruz S, Gerber N, Schmutz EA, Puder JJ, et al. Interventions to promote fundamental movement skills in childcare and kindergarten: a systematic review and meta-analysis. Sports Med. 2017:47:2045-68.

43. Burgi F, Meyer U, Granacher U, Schindler C, Marques-Vidal P, Kriemler S. Relationship of physical activity with motor skills, aerobic fitness and body fat in preschool children: a cross-sectional and longitudinal study (Ballabeina). Int J Obes. 2011;35:937-44.

44. Taylor RW, Williams SM, Farmer VL, Taylor BJ. Changes in physical activity over time in young children: a longitudinal study using accelerometers. PLoS One. 2013;8:e81567.

45. Baranowski T, Thompson WO, Durant RH, Baranowski J, Puhl J. Observations on physical-activity in physical locations - age, gender, ethnicity, and month effects. Res Q Exerc Sport. 1993;64:127-33.

46. Hinkley T, Crawford D, Salmon J, Okely AD, Hesketh K. Preschool children and physical activity: a review of correlates. Am J Prev Med. 2008;34:435-41.

47. Bauman AE, Reis RS, Sallis JF, Wells JC, Loos RJF, Martin BW. Correlates of physical activity: why are some people physically active and others not? Lancet. 2012;380:258-71.

48. Hands B, Parker H, Larkin D, Cantell M, Rose E: Male and female differences in health benefits derived from physical activity: implications for exercise prescription. 2016

49. Buss AH, Plomin R. Temperament: early developing personality traits. Hillsdale: Lawrence Erlbaum; 1984.

50. Goldsmith HH, Buss AH, Plomin R, Rothbart MK, Thomas A, Chess S, Hinde RA, McCall RB. Roundtable: what is temperament? Four approaches. Child Dev. 1987;58:505-29.

51. Rothbart MK, Ahadi SA, Evans DE. Temperament and personality: origins and outcomes. J Pers Soc Psychol. 2000;78:122-35.

52. Irwin JD, Johnson AM, Vanderloo LM, Burke SM, Tucker P. Temperament and objectively measured physical activity and sedentary time among Canadian preschoolers. Prev Med Rep. 2015;2:598-601.

53. Janssen JA, Kolacz J, Shanahan L, Gangel MJ, Calkins SD, Keane SP, Wideman L. Childhood temperament predictors of adolescent physical activity. BMC Public Health. 2017;17:8.

54. van Sluijs EM, MCMinn AM, Inskip HM, Ekelund U, Godfrey KM, Harvey NC, Griffin SJ. Correlates of light and moderate-to-vigorous objectively measured physical activity in four-year-old children. PLoS One. 2013;8:e74934.

55. Hesketh KR, Lakshman R, van Sluijs EMF. Barriers and facilitators to young children's physical activity and sedentary behaviour: a systematic review and synthesis of qualitative literature. Obes Rev. 2017;18:987-1017.

56. Irwin JD, He MZ, Bouck LMS, Tucker P, Pollett GL. Preschoolers' physical activity behaviours - Parents' perspectives. Can J Public Health. 2005;96:299-303.

57. Edwards MJ, Jago R, Sebire SJ, Kesten JM, Pool L, Thompson JL. The influence of friends and siblings on the physical activity and screen viewing behaviours of children aged 5-6 years: a qualitative analysis of parent interviews. BMJ Open. 2015;5.

58. Cleland V, Timperio A, Salmon J, Hume C, Telford A, Crawford D. A longitudinal study of the family physical activity environment and physical activity among youth. Am J Health Promot. 2011;25:159-67. 